Leung, P.P.Y. and Chan, C.L.W. (In-press). Utilizing Eastern Spirituality in clinical practice: A qualitative study of Chinese women with breast cancer. The Smith College Studies in Social Work, 80(2 ), 159-183. DOI: 10.1080/00377317.2010.483673

\title{
UTILIZING EASTERN SPIRITUALITY IN CLINICAL PRACTICE: A QUALITATIVE STUDY OF CHINESE WOMEN WITH BREAST CANCER
}

\author{
Pamela Pui Yu LEUNG, BSW, PhD, RSW \\ Assistant Professor, Department of Social Work and Social Administration, \\ Honorary Research Fellow, Centre on Behavioral Health, the University of Hong Kong
}

Cecilia Lai Wan CHAN, BSocSc, MSocSc, PhD, RSW

Si Yuan Professor in Health and Social Work, Professor, Department of Social Work and Social Administration, Director, Centre on Behavioral Health, the University of Hong Kong

Correspondence should be addressed to:

Dr. Pamela P.Y. Leung, Assistant Professor, Department of Social Work and Social Administration, 13/F, KK Leung Building, The University of Hong Kong, Pokfulam, Hong Kong.

Tel: 852-2859-1185

Fax: 852-2858-7604

Email: pamelalt@ hku.hk 


\title{
UTILIZING EASTERN SPIRITUALITY IN CLINICAL PRACTICE: A QUALITATIVE STUDY OF CHINESE WOMEN WITH BREAST CANCER
}

\begin{abstract}
Drawing on the empirical findings of a qualitative study on Chinese women with breast cancer, this paper presents the women's experience of spirituality and discusses the implications of culturally competent practice that addresses spirituality. Following the constructivist research approach, in-depth interviews were conducted with 26 Chinese women with breast cancer. The findings reveal their spirituality is manifested through (1) experiencing a spiritual shock, (2) making meaning, (3) achieving connectedness, and (4) transcendence. The Eastern cultural teachings of embracing suffering, letting go and living in the moment, and meditative practice have important implications for social work practice. Culturally competent practice requires social workers to appreciate the diverse ways that clients use spiritual resources and reflect on how our own spirituality may affect intervention.
\end{abstract}

Keywords: Spirituality, Eastern, Chinese, meaning, connectedness, transcendence, cancer 


\section{UTILIZING EASTERN SPIRITUALITY IN CLINICAL PRACTICE:}

\section{A QUALITATIVE STUDY OF CHINESE WOMEN WITH BREAST CANCER}

The past decade has seen a resurgence of interest within the social work profession to include spirituality in clinical intervention (Canda \& Furman, 1999). Increasing empirical evidence also supports the role of spirituality in affecting positive outcomes in individuals. In a review by Hodge (2001), spirituality was found to be a significant variable in recovery from divorce, homelessness, sexual assault, and substance abuse. Daily spiritual experiences may mitigate physical, cognitive, and emotional burnout (Holland, Currier, \& Neimeyer, 2006), and spiritual practice was found to be correlated with better health in medical conditions such as heart disease, hypertension, cardiovascular disease, immunological dysfunction, cancer, mortality, pain, and health behaviors (H. K. Koenig, McCullough, \& Larson, 2001; McClain, Rosenfeld, \& Breitbart, 2003).

In light of the recent attempts in social work literature to establish spirituality as an important topic for social work practitioners, attention should be paid to diversity in spirituality and spiritual practice among people with different cultural backgrounds. Culturally competent practice depends, among other things, on understanding and appreciating clients' spiritual belief and resources (Gilligan \& Furness, 2006). Social work practitioners must give greater priority to exploring both the potential significance of spirituality in professional practice and the culturally diverse ways that clients use spiritual resources in daily life. In contrast to Western discourse of spirituality, mostly influenced by a Judeo-Christian perspective, Eastern spirituality reflects a secular orientation with a strong contemplative tradition and unique concerns rooted in Confucianism, Daoism, and Buddhism. Harmonious interconnectedness, concern with selfknowledge and inner peace, relationship of self and others, and connection of human beings and 
the larger context are core concepts. Transcendence is achieved through ceaseless efforts of selfcultivation and contemplative practice.

This paper introduces the Eastern concept of spirituality. We draw on the empirical findings of a qualitative study of 26 cancer patients, to discuss the spiritual resources available from Eastern culture that are helpful to clients who are coping with life crises related to cancer. Discussion of implications for culturally competent and spiritually oriented social work practice follows.

What is Spirituality?

Spirituality includes the multidimensional aspects of human experience and entails cognitive, philosophical, experiential, emotional, and behavioral components (Chan, $\mathrm{Ng}, \mathrm{Ho}, \&$ Chow, 2006; Lee, Ng, Leung, \& Chan, 2009). Spirituality is not synonymous with religion. It is related to the way people understand questions on the ultimate meaning of life, illness and death, the state of peace, harmony, and transcendence of living. The concept of spirituality embodies values of an individual, a connection to a vital force or a sense of deeper self (Lee, et al., 2009).

\section{Eastern Spirituality}

Eastern culture is influenced most significantly by Confucianism, Buddhism, and Daoism. These traditions have shaped the civilization of China and Southeast Asia for more than 2000 years and are the roots of Eastern spirituality. Eastern spirituality embraces a number of core values and beliefs that govern how an individual sees the world, the self, and how one leads one's own life. These values and beliefs include the capacity for continuous self-realization; connectedness and harmony with self, others, and the universe; appreciation of the changing nature of life and embracing whatever is in the present moment; endurance and transcendence of suffering and pain; and the striving for higher goals such as compassion and loving kindness 
(Dalai-Lama \& Cutler, 1998; D. Y. F. Ho \& Ho, 2007; Lee, et al., 2009). Suffering is a path to a higher level of spirituality. These core values and beliefs are discussed below.

\section{Continuous Self-realization}

In Confucianism, human personhood, our original nature, is endowed by Tien $^{l}$, a deity or Heaven $(\mathrm{Tu}, 1985)$. It is believed that within our heavenly endowed nature are our intrinsic kindness, goodness, and greatness, which were originally latent. Through the conscious and ceaseless effort of self-cultivation, we can realize our human nature fully and attain selftranscendence. Thus, in Confucian thought, the ultimate purpose of life is self-realization. When a person strives to fulfill his or her potential and manifests or lives the virtues of forbearance and endurance, spiritual capacity grows. This conception can be understood as a source of resilience in Eastern culture. In The Book of Mencius, a classical text in Confucianism, it is written:

When Heaven is about to confer a great responsibility on any man, it will exercise his mind with suffering, subject his sinews and bones to hard work, expose his body to hunger, put him to poverty, place obstacles in the paths of his deeds, so as to stimulate his mind, harden his nature, and improve wherever he is incompetent. (Tu, 1985, p. 62)

Suffering is viewed as the Mandate of Heaven to test a person's resolution and toughen his or her nature $(\mathrm{Tu}, 1985)$. As such, suffering can have positive meaning and provide a context for spiritual growth. This belief in suffering as a test can foster strength, resilience, and inner capacity to take on social and communal responsibilities for the common good. Suffering and adversity can be seen as a gift of life. Thus, the belief of the deeper meaning of suffering can lead to a search for self-fulfillment and transformation. Seeing suffering and adversity as a pathway to growth can introduce a new perspective on why individuals should stay with suffering to regain an internal locus of control. 
Eastern spirituality emphasizes the interconnectedness of self and others and the importance of the context and relationships with the environment and universe. Human beings are perceived as embedded in and dependent on the larger dynamics of the family, the community, and nature (Tucker, 2003). As such, self-realization is more than individuation or self-actualization but a process of connecting with the authentic nature of the self, harmonizing interpersonal relationships, respecting and nurturing all living things, and harmonizing with changes in the universe. In the process of realizing one's full humanity, an individual strives to be in consonance with the creative and generative powers of Heaven and Earth that transcend the self. The transcended person lives in accord with tien-ming, the Mandate of Heaven (Jing, 2002; Tu, 1998) and attains the state of tien-ren-he-yi, the unity of humankind with Heaven (Tucker, 2003; Yu, 2003), meaning human beings harmonize and become one with Nature.

\section{Life is Constantly Changing}

In Daoist philosophy, life is the eternal dynamic dance between two opposite, mutually facilitating and repressing forces, yin and yang. Yin represents softness, stillness and shadow; yang represents hardness, movement and light. The yin and the yang intertwined, ever-changing in a cybernetic manner, give rise to dynamic balance for everything in the world. Reality is a process of constant flow and change governed by these natural forces (T. L. Koenig \& Spano, 1998). Human lives are meant to be confronted with both desirable and undesirable experiences. Thus, Daoism entails a trust in the universal rhythm to do what it will do. The Daoist belief is that allowing human life and nature to unfold in its own way and relinquishing the effort to control are ways for generation, peacefulness, and harmony (Tsuei, 1992). The way to transcend loss and suffering brought about by misfortune, illness, and failure is to accept it and let go of the psychological attachment to comfort and possession. The ability to be in harmony with periods 
of crisis depends on an individual's capacity to embrace whatever is in the present moment. Accepting life as unpredictable and not always within our control helps an individual to flow with the crisis (Chan, Ng, et al., 2006; T. L. Koenig \& Spano, 1998).

\section{Transcending Suffering}

Buddhism is primarily concerned with freeing people from suffering and attaining awakening. The Four Noble Truths are the central teaching of the Buddha (Ramaswami \& Sheikh, 1989; Rubin, 1996). The essence of the Four Noble Truths is:

- Life is inherently suffering. The suffering of birth, old age, sickness, and death are the basic sources of suffering in life and are inevitable.

- The real causes of suffering in human life are desire, attachment, and craving, the desire and craving for sense gratification, continuity of self, and attachment and clinging to possessions, ideals and concepts.

- The eradication of suffering begins with awareness that life is impermanent, and one must let go of over-attachment in life.

- Ultimate transcendence is the state of liberation from suffering. It can be attained through the Eightfold Path, which concerns right aspiration, speaking truthfully and compassionately, abstaining from doing bad deeds, engaging in actions that promote life, and maintaining an effort to get right awareness and see things as they are through mindfulness practice ${ }^{2}$ (Rubin, 1996).

The four Noble Truths provide the way to understand and transcend human suffering. Awareness that life is impermanent is the way to cease suffering and attain spiritual enlightenment. Through meditative practice and other efforts, an individual can remain peaceful with whatever comes and exhibit the noble qualities of compassion and loving kindness. 
Moreover, non-attachment to pleasure and pain and to relationships is important in understanding, accepting, and ending suffering. Appreciating the vulnerability of life and being able to develop an innate sense of peace and fulfillment are the goals of transformation through pain. Seeing the deeper meaning of loss, hurt, and suffering can be liberating; it can inspire hope and help attain a sense of coherence.

\section{Karma: Interdependent Nature of Cause and Consequence}

The Law of Cause and Effect is the ontological basis of Buddhism, which states that all phenomena originate in a cause-and-effect relationship, karma. All phenomena are conditional; one phenomenon will lead to the next. Bad things occur because of the debt of bad karma. Good deeds can sow good karma for the future. Compassion for others, not hurting the self and other creatures, and performing altruistic acts is good karma that accumulates credits in heaven. These are important values in Eastern spirituality.

\section{Cancer and Spirituality}

A cancer diagnosis may alter an individual's life significantly in the physical, psychosocial, and spiritual domains (Highfield, 1997; Thornton, 2002). Cancer confronts an individual with challenging tasks such as dealing with treatment side effects, facing physical changes and altered body image, handling changes in role performance, social relationships, dealing with uncertainty, fear of recurrence, and a disrupted sense of identity (Fife, 1994; Samarel et al., 1998; Zebrack, 2000). Adaptation to these stressors may require an individual to use a variety of coping strategies. Cognitive coping theory proposes two major types of coping strategy: problem- and emotion-focused coping (Lazarus \& Folkman, 1984). Problem-focused coping is an attempt to manage the stressor and use problem-solving strategies. Emotion-focused coping deals with the distressful feeling associated with the stressor through such measures as 
distancing, escape-avoidance, and positive reappraisal. A recent meta-analysis on appraisals and coping in people living with cancer suggests that individuals who appraise their illness as a threat or challenge are likely to use more problem-focused coping strategies, and those who appraise their cancer as a harm or loss are likely to use more avoidance coping strategies (Franks \& Roesch, 2006).

Because of the life-threatening effect of the illness, people with cancer may also struggle with the spiritual question of why, feel at a loss with a heightened awareness of the reality of mortality, and try to make sense of the circumstances of their life. Studies reveal that between $41 \%$ and $94 \%$ of cancer patients want discussions on spiritual issues with their health-care practitioners (Daaleman \& Nease, 1994; Ehman, Ott, Short, Ciampa, \& Hansen-Flaschen, 1999). Patients want help in finding hope, meaning in life, and spiritual resources (Moadel, Morgan, Fatone, Grennan, \& Carter, 1999). Cognitive coping theory may be inadequate in addressing a patient's adaptation when spiritual/existential issues are primary concerns. Recently, literature on meaning-based coping and religious/spiritual coping is receiving increasing attention in psychooncology (Folkman \& Greer, 2000; Thune-Boyle, Stygall, \& Keshtgar, 2006). A systematic review suggests that religious/spiritual coping serves to promote adjustment to cancer by maintaining self-esteem, providing a sense of meaning and purpose, giving emotional comfort, and providing a sense of hope (Thune-Boyle, et al., 2006).

There is also growing literature on positive spiritual outcomes among cancer survivors. This literature suggests that cancer patients experience a change in personal life priorities, renewed recognition and greater appreciation of life, and stronger faith and better understanding of spiritual matters (Cordova, Cunningham, Carlson, \& Andrykowski, 2001; S. M. Y. Ho, Chan, 
\& Ho, 2004; Komura \& Hegarty, 2006). Serious illness can be a valuable opportunity for spiritual renewal (Chan, Ho, Fu, \& Chow, 2006).

The research literature on spiritual resources for cancer patients primarily involves qualitative studies. For example, Gall and Cornblat (2002) found spiritual resources used by breast cancer patients that include their relationship with God, religious coping activities, meaning, and social support. Using focus group interviews, Ashing, Padilla, Tejero, and Kagawa-Singer (2003) showed that Asian American women used their spiritual beliefs to cope with breast cancer. Another study on Chinese American women with breast cancer reported that traditional Chinese values, family closeness, religion, alternative therapy, and Chinese support groups were spiritual resources for them (Chiu, 2001).

Despite the burgeoning literature on cancer and spirituality, most studies have involved a Western sample or are conducted in the West. Given that spirituality is a culturally sensitive construct, these studies are limited in their ability to inform spirituality oriented practices in diverse cultures. Moreover, existing studies focus on patients' spiritual needs, spiritual growth as an outcome of cancer, and types of spiritual resource used by cancer patients. No study focuses on how patients use spirituality in adjusting to the diagnosis and treatment of cancer. Understanding how patients from an Eastern cultural context draw on spiritual resources may give valuable insights to inform culturally sensitive intervention for social work practice. Recently, our team conducted a qualitative study on the experiences of Chinese women in Hong Kong. We find spirituality a significant component in these women's experience and a source of coping strengths for them (Leung, 2007). In light of these findings, this paper discusses how knowledge of spirituality of Chinese women and Eastern spiritual resources can inform culturally competent social work practice in working with people who suffer from serious illness or loss. 
Method

A constructivist qualitative approach was used to obtain Chinese women's narratives (Guba, 1990). In-depth interviews were conducted with Chinese women ages 18 and over, diagnosed with primary breast cancer. Purposive sampling was used so that women with a wide variety of demographic backgrounds such as age, educational level, marital status, religious affiliation, and employment status were included (Patton, 2002). Excluded were women who had other major medical problems, a history of major psychiatric illness, or who were illiterate. Data saturation, defined as no new codes generated over three consecutive interviews, was achieved with 26 women. Ethical approval was obtained from the Institutional Review Board of the Hospital Authority of Hong Kong. A detailed explanation of research purposes, procedures, and rights of the participants was given before written informed consent was sought. The interview topics included how participants made sense of the cancer and their experience; what effect the experience had on them; changes in relationships with self, others, and a higher power; and their spiritual beliefs, practices, and other coping resources. Examples of questions are: "What is the meaning of the illness for you?" "What are your sources of strength while living with breast cancer?" Probes aimed to gain deeper understanding of the participants' interpretation of the meaning of their experiences and were guided by the participants' responses. Analysis was carried out with the help of the NUDIST Nvivo package. Transcripts were reviewed line by line and coded (Charmaz, 2003). The codes were then scrutinized, clustered, and organized into themes and conceptual categories. An iterative method of analysis based on the constant comparative technique (Charmaz, 2003; Strauss \& Corbin, 1990) was applied to review all transcripts. Data collection and analysis were an ongoing iterative process. Data from new transcripts were used to assess the emerging framework, and themes were affirmed, refined, 
or altered. The validity of the codes and themes was checked by a psycho-oncology researcher uninvolved in the project. Memos kept by the researcher facilitated the conceptualizing process and enhanced research rigor, reducing the potential for bias (Lincoln, 2002; Morrow, 2005; Padgett, 2008). Periodic discussions were held with the research team to scrutinize the plausibility of the themes and patterns observed, and to address reflexivity issues. Quotations from the transcriptions in Chinese were translated into English and checked for validity.

\section{Sample Characteristics}

Twenty-six women were interviewed. The age range at the time of interview was 25 to 69 , averaging 49.7. These women represent a diverse range of personal and social backgrounds in education, employment, marital status, living arrangements, and religious affiliation. Their demographic characteristics are summarized in Table 1. For anonymity, pseudonyms are used.

Insert Table 1 about here

\section{Results}

Analysis revealed that spirituality is a significant component in Chinese women's experiences of adjustment to cancer. Spirituality was manifested in four major themes: (1) experiencing spiritual shock, (2) meaning-making, (3) connectedness, and (4) transcendence. These four themes and the sub-themes grouped under them are presented in Table 2. Findings also revealed that the majority of women found that Eastern cultural teaching and spiritual practices helped them cope with breast cancer by empowering them and giving them inner strength and a sense of peace. Each theme is discussed, with supportive quotes from the woman's narrative.

Insert Table 2 about here

Experiencing Spiritual Shock 
The experience of spirituality in women with breast cancer is an evolving process. For many women, the initial phase involved a spiritual shock, during which they asked why and experienced a loss of "self."

I have never done bad deeds... I don't steal. I don't say bad things about other people. I work hard... Why did I get cancer? After the diagnosis, I kept asking myself why I must be the one subjected to this torture. (Ivy)

I lost my energy at work, just like I have lost my "self” in my mind. It's hard and I feel anxious to find my original self...It was really defeating.... It was a spiritual trauma." (Daisy)

The women found it difficult to make sense of the experience, as the occurrence of cancer was not coherent with their existing core belief that good people deserve good things. The loss was experienced like a "spiritual trauma."

\section{Meaning-Making}

When the women were able to face reality, they began to search for meaning and to help themselves cope with the losses and difficulties. Meaning-making involves the coping activities of an individual after a loss: giving an explanation for what happened, finding significance, and regaining a sense of coherence (Davies, Wortman, Lehman, \& Silver, 2000; Neimeyer, 2001; Park \& Folkman, 1997). These women created meaning by attributing a cause to the occurrence of cancer, construing benefits in the experience, and restructuring an alternative life perspective.

\section{Attributing a Cause to the Occurrence of Cancer}

The majority of women who attributed cancer to a cause explained it with spiritual terms, followed by physical terms, and then psychological terms. Data revealed that the spiritual attribution derived by women included the cultural beliefs of tien-ming, karma, and the will of God. 
Cancer as tien-ming. Many Chinese people who do not adhere or practice any religion believe in Tien. Betty was one of them. She regarded cancer as Tien's will to test her mind and strengthen her resolution.

I conceived of it [the cancer] as a test from Tien. Tien used it as a challenge to my strength... Tien was testing my mind and to see if I would yield to the disease. It tested whether I persevered or not.

I think my willpower is strong. I won't be defeated by this test and won't let myself be defeated in any situation. The greater the challenge, the stronger my willpower.

Cancer as karma. Ivy assumed the world was benevolent and it would be unjust if good people like her got cancer. In her early forties she was diagnosed with breast cancer. She felt miserable, as she thought she did not deserve it. She said, "I asked why it was so unjust." When Ivy learned Buddhist teachings, she developed a new perception of her illness. She attributed it to karma. She believed that cancer was the result of misdeeds in previous lives and developed a totally new perspective on her experience:

Now, there is no need to ask why... why I got cancer... I didn't know what the "cause" was, as it happened in previous lives. I am just getting the "result." I have to take the result, as it is karma. Just like when you have a loan, you have to repay the money... My thinking is now I am reaping what I have sown in previous lives. At the same time, I am sowing seeds for the future... Therefore, I will seize the present, be positive, and sow good seeds of karma for my future lives.

Ivy got an answer for her suffering. Instead of asking the cause, she began to focus on her spiritual life and engage in altruistic activities to build good karma.

Cancer as the will of God. Doris was a Christian. She got cancer at the age of 54. In her mind, cancer was only for very old people. As she did not have a family history of cancer, Doris could not make sense of the reason for the illness. Later, when she reflected on her life, she thought it might be God's will. She perceived cancer as a reminder from God asking her to be more faithful and to spread Christianity. 
Would it be God's will for me to have this experience? In my daily life, I did not do anything wrong. Maybe... I think... it's because I've never passed on to other people the good news of God. As a Christian, we should offer service to God and spread God's news. For the last 20 years, I've been helping with my family's business and taking care of the children. But I've never offered service to God... God is now using me to witness to others His almighty power.

Asking why is a common reaction to a serious illness like cancer. An ability to explain the event helps make sense of what happened and enhances adaptation (Taylor, 1983).

\section{Restructuring the Perspective on Life}

In addition to assigning attributions on the cancer, participants reappraised the fundamental assumptions they held about the world. They reestablished a life perspective that could serve as a guide for future living. They spoke of "realizing life as impermanent," "many things in life are unpredictable," and "life is changing all the time." This realization was not only a cognitive shift in how the women perceived the world and their place in it but also an experiential revelation, as they experienced being "close to mortality." The women's narratives show that a new perspective that includes the notion of impermanence and change replaced the old ones. Recognizing the transient nature of life and appreciating change, the women cherished the present and focused on searching for the meaning of the experience in particular and life in general. This came for some women with a major shift in how they approached their daily lives.

\section{Construing Benefit in the Experience}

The Confucian notion that suffering can be a "blessing in disguise" fits the experience of women who found their lives enriched by the ordeal of illness. They reported "feeling stronger," "experiencing a sense of self-reliance," and "having better capability to deal with future adversity." In the process of coping, women learned to "build the self up," "take responsibility," and "appreciate one's potential." Doris's story is perhaps the best example of how spirituality was manifested through striving for meaning and personal growth in suffering. Doris perceived 
cancer as a reminder from God. Previously her life goal was to be self-sufficient. She lived in her own personal universe without concern for things outside her daily life. The sudden onset of cancer was a wake-up call for Doris to explore new ways of living in accord with God's will. She attended courses to learn how to preach and to serve others, and devoted herself to missionary duties. In sharing teachings about God with people from different walks of life, Doris found a deepened connection to others and God and realized her courage and unused potential:

I don't know how long I'll live, but I'm happy; I treasure every day... inner peace is definitely more important than any other thing in the world... I would like to use the rest of my time in this life to glorify God and to share with other people my gratitude to Him.... Recently, I learned to use Cantonese opera as a means to spread the message of God. I went to a home for the elderly to visit the people and share with them Cantonese opera.

Her personal growth from the illness was evident:

This is personal growth; I see the courage inside me. In front of that big audience, I shared the story of my illness as a testimony to God's almighty power. I can make it.... I live a fuller life now; spiritually, I am happier, I am stronger. I am a different person.

Other women in this study reported having developed new interests and making new friends, which they found made their lives more fulfilling. Some took early retirement because of the illness, some seized the time to do things they enjoy and try new hobbies. Realizing that life is not infinite prompted these women to get the most out of their lives.

\section{Connectedness}

The essence of connectedness is relationship and a sense of closeness. The women developed a deeper relationship with themselves, with others, and with God/Tien. A sense of appreciation and closeness was pervasive in their experience.

\section{Relationship with Self}

Data revealed a core concept on the relationship with self, zizai, literally feeling at ease. It is a Chinese concept encompassing a feeling of contentment, peace of mind, deep relaxation, and 
bliss. It is a state of being in the present moment and getting in touch with one's true nature. Zizai was experienced by women as being "worry free," the result of "taking things easy," "being unattached," and "letting go." Amy's story illustrates the profound effect of reconnecting with one's true nature and spiritual self after cancer. Amy was born into a traditional maleoriented Chinese family and learned the stereotypical female role of self-sacrificing nurturer when she was young. Living in accord with the ideal role of a filial daughter, Amy focused only on the well-being of others, always sacrificing for the family. During her illness, Amy contemplated deeply who she was and how she would like to lead her life. She said, "The question 'who am I?' often pops into my mind... I sometimes ask myself who is this 'self'?” Amy realized that she had been living in accord with the cultural prescriptions of an ideal filial daughter but lost her own "self." She decided to free herself from the constraints of perceived social obligations and started to develop new interests and enjoy life. "I have learned what equality and love mean. In the past, giving love to others was one way.... Equality means every human being is capable of giving and receiving love." She started to enjoy being cared for by other people. She took more time for herself, to attend to her own needs and aspirations. She said: "Now I feel very zizai! Since I got sick, I have let go... I'm worry free, like sitting there and just relaxing; it's so comfortable.... Letting go of attachments of the heart, I feel more relaxed." She gained a sense of freedom and spontaneity when she let go of the attachment to an ideal cultural self.

Other women spoke of experiencing a deepened connection with the self in doing qigong ${ }^{3}$ and meditation. They described the experience as "untying the self" and "achieving psychological flexibility." Ivy learned Buddhist meditation after her illness; she stated it helped her to connect her body and mind and become grounded: 
Calm and center the body and the mind. Let your body, mind, and spirit be grounded, steady, and calm, grounded with an insight, grounded in stillness.

\section{Relationship with Others}

Experiencing connectedness with others was evident in several ways. The experience of feeling sick and vulnerable brought about a heightened awareness of the importance of family members and friends. The common support the women experienced included being accompanied for medical visits, being offered food and tonifying soup, receiving emotional support and so on. They reported "feeling touched and grateful" and "having a closer relationship." One salient feature of their experiences was the development of the ability to care for others. Karen's narrative is a good illustration:

When I was sick, people around me were very caring. ... Previously, I didn't recognize how good it was to be cared for by others.... When I really needed help from the people who care about me, I felt the warmth as if I was holding a hot water bottle. It was very warm, very warm indeed.... Now I want to take a reciprocal role to care about others.

The cancer experience also changed her perspective in life.

I learned not only to cherish my health but also my family, my friends, my husband.... Now I pay attention to how they feel. I care about their feelings... Previously, I was too self-centered.... I only focused on myself; it was not very good.... I changed the way I relate to others.... I am not as self-centered. This is a new meaning in the experience.

When the women were able to open the self to others, they experienced a new meaning and a renewed sense of connectedness with other people.

\section{Relationship with God/Tien}

In discussing questions about spirituality, the participants frequently spoke of their relationship with the ultimate power they believed in, God or Tien.

Faith in God. Faith in God was an important source of strength and hope for women who have religion. Some reported vividly experiencing God's care when they were ill. For example, Gloria said: 
God gave me a nice angel to cure me, not only my body but also my mind. I thank God for leading me through the valley of the shadow of death! It brightened up my life! I love God more because of this experience.

An expression of gratitude to God was also pervasive in Queenie's personal account:

When I look up to the sky, I thank God very much for the salvation and regeneration He bestowed on me. After completing chemotherapy, I felt that I was a different person.... In the process of recovery, my hair became very dark and curly, which became the envy of everybody who saw it. I thank God for it.

Some women experienced spirituality through reconnecting with God. Tina's story best illustrates this. Tina was a Christian but her faith was not very strong. After getting cancer, she rested at home and had time to reflect on her life and her relationship with God.

I think [in the past] I did not attune my mind and spirit... I did not pray. My faith was not very strong. I had nothing to rely on, no one to share with. Therefore... when I was sick, I realized that God used the illness to save me.

I realized that God has a will when He let me experience every process....as I felt that $\mathrm{He}$ has been taking care of me all along.... I shared with my friend the feeling that when God placed me in adversity, He was actually giving me the opportunity to learn to rely on Him... I spend much more time in prayer....I leave my entire burden to God.... There is no need to worry then... God has heard my prayers.

Unity with Tien. For those who believe in the power of Tien, unity with Tien is a profound transcendental experience that is potentially life-changing. Crystal had led a comfortable life ever since she was born. Her aspiration was to earn money and pursue material comfort. Cancer was a defeating experience, as her ability to earn money was diminished after the treatment. As part of her rehabilitation program, she learned to practice qigong. She was taught to live in harmony with the flow of life bestowed by Tien. When she was doing qigong, she focused on the moment-by-moment experience. Her experience was a "unity with Tien" in which she found liberation and joy:

I believe that up there is the Ultimate Being who takes charge of this world. There is no need to bother [with why I got cancer]. I'll walk in whatever way is designated by Tien. I recognized that this is the way to achieve happiness.... Just follow the will of Tien... 
Everything that He gives you, from birth to death, is written on a list. You just follow what Tien asks you to do. Life will then be lived happily.

\section{Transcendence}

Transcendence involves understanding the self in a larger context, defining one's relationships with oneself, others, humanity, nature, and some higher power; thus it gives meaning and purpose to life (D. Y. F. Ho \& Ho, 2007). According to Wilber (2000), transcendence is a process of integration of the self for greater wholeness. It goes beyond a narrow vision of the self, individuality, and self-actualization but encompasses trans-egoic value and experience. Transcendence captured the spiritual experience of women in this study, including sub-themes of revival and transformation, nurturing compassion, being in harmony with Nature, and living in the present. Each of these sub-themes is discussed below.

\section{Revival and Transformation}

Tina described her experience as a revival through suffering. Before cancer, her life was “just work, work, work, without any meaning." Working life was such a burden that she felt like “a walking corpse, a living dead person." She believed that God used the cancer experience to make her rest and "resuscitate" her.

What the cancer experience has given me is not suffering but a chance to be resuscitated by God... I felt that it was miraculous when God made this event [cancer] happen to me... I learned not to focus on the suffering I experienced in hard times but on what lessons were there for me and the gain I could get from them... what the cancer experience has given me is... a chance to be revived. The revival is granted by God.

Other women spoke of the cancer experience as "a transformative experience that generated a positive life force," "a miraculous journey that fostered personal growth." For these women suffering became a path to a higher level of spirituality. 
Having survived the hardship of the illness, the women spoke of "having an increased sense of compassion for those who were suffering," "becoming more empathetic," and "gaining a sense of meaningfulness in using the experiences of the illness in helping other patients." Ivy's narration demonstrates how the experience nurtured compassion and deepened her understanding of the needs of others who suffered:

Previously, I didn't know how much a patient needs others' care and support. After this illness, I know how to care for other people... I can put myself in someone else's shoes... this makes me have such a call to actively approach other people in need.... For example, I take the initiative to call my friend whose husband has been diagnosed with cancer, to give her support. I know when I should call her and what to say... I'm also a patient. I've been ill. I have the same experience. I know what a patient needs.

In her personal account, Ivy shared how caring for others helped in her spiritual healing:

At that period when life was full of uncertainty, I was helpless and anxious; I needed support... I needed something that could support me spiritually. ... Now I know I can use my compassion. In the morning when I meditate on the Buddha's teaching, I send my blessing to other people and other living creatures. If not for this illness, I would not have the opportunity to learn about the teachings of the Buddha. This change has brought me many gains.

In the 1960s, Frank Riessman (1965) advocated the therapeutic effect of being a "helper." This helper therapy principle is illustrated by Ivy's story of healing herself and moving from a victim role in the process of helping other people.

\section{Being in Harmony with Nature}

The women described moments of experiencing self-transcendence in being close to and feeling at home in nature. Emma found nature a spiritual refuge and found healing. She said, “There's a magical power...that enables me to be in touch with myself and with nature in tranquility. It's to be in touch with my body and mind." Other women spoke of being “joyful," "grateful," "feeling the vitality and freedom," and "united with Heaven and Earth." The women felt part of the Cosmos and viewed the self in the larger context. 


\section{Living in the Present Moment}

"Living in the present moment" was a transcendental experience for many women. The quotes from Flora's narratives describe how she learned to live in the present moment:

Birth, aging, and illness are processes that every human being has to go through. Some people have a longer journey; others walk their life at their own pace without regret. Everyone has to accept what is given by fate or Tien. What matters is, as taught by the Buddha, live in the present. If one lives fully with meaning, one has really lived life.

I won't be holding on as in the past. Live in the present moment... in other words, it's fine if we do our best for today... After having cancer, I live a simple life, living in the present moment.

By living in the present moment, women live one day at a time, living fully and following the heart's desire without clinging to the preoccupations of the mind.

\section{Discussion}

The findings of this study show how spirituality is manifested through experiencing a spiritual shock, making meaning, achieving connectedness and transcendence, and providing coping resources. Eastern conceptions of spirituality entail the notions of ceaseless striving of self-cultivation, transcendence in a deepened connection with others and nature, living in the present, liberation through embracing suffering, and pursuing higher goals of compassion and loving kindness (Chan, Ho, \& Chow, 2001; Chan, Ng, et al., 2006; Dalai-Lama \& Cutler, 1998; Tu \& Tucker, 2003). These conceptions differentiate spirituality from religiosity. An individual can be spiritual and/or use spiritual resources without subscribing to a particular religion. In this study, women who expressed no religious affiliation or those who were Christian seemed to find Eastern spiritual beliefs and practices helpful in their adaptation. Christian participants might integrate both Eastern and Christian beliefs in their adaptation process. However, the nonreligious aspects of spirituality are largely underrepresented in the literature. There is a call for an expansion of the conceptualization of spirituality in Western literature, especially in cross- 
cultural explorations. A cross-cultural examination of the conception of more inclusive spirituality is necessary to address the increasingly diverse needs of clients from different cultures.

Specifically, as the findings of the study indicate, spirituality can be manifested through embracing suffering, letting go, and engaging in tranquil meditative practice. These findings have important implications for social work practices.

\section{Embracing Suffering: A Path for Spiritual Enlightenment}

Confucians believe that hardship, pain, and suffering in life are the ways in which Tien to strengthen willpower and perfect character (Tu, 1985; Tucker, 2003). When the women in this study attributed cancer to Tien's will to test their willpower, they perceived the challenge of cancer as an opportunity to cultivate their capacity for perseverance and resilience. By embracing suffering, the women strived to live in accord with the will of Tien, realizing their heavenly endowed nature of greatness. Suffering has meaning and is a path for self-transcendence. These beliefs can be seeds for the development of optimism and strength for coping and a source of meaning for people facing adversity and loss.

In the women's experiences, belief in karma seems to be empowering and hopegenerating. As cancer is the result of karma, there is no need to bother asking why it happened. Instead, women's attention was drawn to nurturing good seeds of karma through engaging in positive actions that benefit the world. Spiritual healing resulted when the women moved their focus to others' well-being and devoted their efforts beyond egoistic concerns. When an individual transcends suffering and develops genuine compassion for others, or directs the self to a mission or a valuable deed larger than the self, he or she opens to selfless love, creativity, meaning, and appreciation. This moves the self to a position of greater wholeness. 


\section{Letting Go: The Paradox of Taking Charge in Letting Go}

The idea of letting go, rooted in Buddhism and Daoism, is related to the belief that all phenomena are impermanent and constantly changing. Zen Master Thich Nhat Hanh contends that peace is about letting go, as non-attachment from an egoistic mind frees people from narrow-mindedness and preset views (Nhat-Hanh, 1995). When the women in this study talked about letting go, they were talking about relinquishing efforts to control outcomes, forgoing attachment, or clinging to a preset frame of mind and inhibiting thoughts, i.e., realistic, positive, and adaptive acceptance. Paradoxically, letting go seemed to help these women to take charge (Chan, Leung, \& Ho, 1999). Probably, they took charge of the processes of embracing whatever is in the present, appreciating the flow of life, becoming more compassionate, and living every moment more fully.

\section{Eastern Practice: Mindfulness}

Mindfulness practice has gained increasing popularity in the West, and mindfulnessbased therapy is an effective intervention model in the mental health field (e.g. Teasdale et al., 2000). The women in this study described having their body-mind-spirit centered and integrated during the practice. The practice of mindfulness probably helped the women become more aware of their own experiences and reactivity in daily life and developed the capacity to live in the present moment, attain clarity of mind, and nurture compassion (Gunaratana, 1991; Nhat-Hanh, 1991). Thus, mindfulness can help an individual to maintain a sense of inner peace in the face of tragic situations, and enhance the capacity to experience an increased appreciation for life and relationships, delight in simple things, and find joy in ordinary moments.

\section{Implications for Practice}


Influenced by the medical model, mainstream social work practice advocates a stance of active control and mastery of one's own problems and the environment (Siporin, 1983). However, life events such as late-stage cancer and the death of loved ones, and crises like natural disasters, mass terrorist attacks, or accidents constantly remind us how little control we have over the world. In social work intervention, sometimes it is difficult to remove pain and hurt from the loss and trauma that clients experience. Helping clients to embrace the pain and suffering in life is a possible solution. The experiences of the women in this study who used Eastern cultural concepts and the practice of positive acceptance and tranquil meditative practice provide an alternative perspective for coping with traumatic events. The women spoke of zizai, in which they experienced deeper connection with self and freedom from preoccupations of the mind, rumination of thoughts, and emotional burdens. This kind of experience is very healing and even transformative. Embracing suffering and searching for spiritual meaning in suffering can be useful for client empowerment (Leung, Chan, $\mathrm{Ng}$, \& Lee, 2009). In social work practice, we can go beyond our intervention goal of mastering and solving the problem at hand to include searching for meaning, and pursuing inner peace, resilience, and spiritual transformation. Specific implications for practice drawn from such a framework are summarized as follows: 1. Exploring the spiritual value of suffering and looking for its positive meaning for the client. Possible themes of exploration in a therapeutic session can include (for more discussion, see Lee et al., 2009; Leung et al., 2009):

- Affirmation of personal strengths and unused potential, including enhancement of skills and capacity

- Discovering change in personal values, aspiration in life, perspectives, and worldview (the way one sees the world and the self) 
- $\quad$ Discovering change in relationship with and way of relating to others

- Discovering change in relationship with God (or whatever the client believes to be the ultimate being).

2. Facilitating value clarification and identifying new possibilities or paths for one's life.

3. Promoting connectedness through appreciation. Appreciating pain, life, self, other people, and nature are therapeutic elements to healing and paths to more intimate relationships.

4. Facilitating positive acceptance and letting go when elimination of the problem is not possible. Pursuing inner peace and focusing on what one can proactively do instead of holding on to things that one cannot change.

\section{Conclusion}

The small number of participants may limit the generalizibility of the findings of this study. The retrospective nature of data collection may also involve recall bias. However, the findings contribute depth of understanding and valuable insights to the relatively understudied phenomenon of spirituality experienced in the East. The findings offer a culturally relevant account of how spirituality is manifested in Chinese women in the context of illness and coping. Eastern cultural concepts such as tien-ming, karma, impermanence, letting go, non-attachment, connectedness, and transcendence through suffering represent a wealth of resources that can help clients to cope during life crises. Appreciating and honoring the culturally diverse ways our clients use spirituality in daily life, and in coping with crises, should be given greater priority in social work. What is more, culturally competent practice requires reflexivity for social work practitioners to reflect on how our own spirituality may affect intervention in the therapeutic encounter. The challenge is helping clients to see their spiritual values and beliefs as part of the solution to their problems, without trying to challenge or change those values or beliefs. Value 
clarity—reflection on our own spiritual values that may come into the helping relationship and have shaped our own practice — and respect, client centeredness, and inclusiveness are important guiding principles in working with clients from diverse spiritual backgrounds (Canda \& Furman, 1999).

\section{Acknowledgements}

This study was funded by a grant from the Research Grants Council of the Hong Kong Special Administrative Region, China (Project No. HKU 7212/03H) and a research grant from the Hong Kong Cancer Fund. 


\section{References}

Ashing, K. T., Padilla, G., Tejero, J., \& Kagawa-Singer, M. (2003). Understanding the breast cancer experience of asian american women. Psycho-Oncology, 12(1), 38-58.

Canda, E. R., \& Furman, L. D. (1999). Spiritual diversity in social work practice: The heart of helping. New York: Free Press.

Chan, C. L. W., Ho, P. S. Y., \& Chow, E. (2001). A Body-mind-spirit model in health: An Eastern approach. Social Work in Health Care, 34(3/4), 261-282.

Chan, C. L. W., Ho, R. T. H., Fu, W., \& Chow, A. Y. M. (2006). Turning curses into blessings An Eastern approach to psychosocial oncology. Journal of Psychosocial Oncology, 24(4), $15-32$.

Chan, C. L. W., Leung, P. P. Y., \& Ho, K. M. (1999). Empowering Chinese cancer patients: Taking culture into account. Asia Pacific Journal of Social Work, 9(2), 6-21.

Chan, C. L. W., Ng, S. M., Ho, R. T., \& Chow, A. Y. M. (2006). East meets West: Applying Eastern spirituality in clinical practice. Journal of Clinical Nursing, 15, 822-832.

Charmaz, K. (2003). Grounded theory. In J. A. Smith (Ed.), Qualitative psychology: A practical guide to research methods (pp. 81-110). London: Sage Publications.

Chiu, L. (2001). Spiritual resources of Chinese immigrants with breast cancer in the USA. International Journal of Nursing Studies, 38(2), 175-184.

Cordova, M. J., Cunningham, L. L. C., Carlson, C. R., \& Andrykowski, M. A. (2001). Posttraumatic growth following breast cancer: A controlled comparison study. Health Psychology, 20, 176-185.

Daaleman, T. P., \& Nease, D. E. (1994). Patient attitudes regarding physician inquiry into spiritual and religious issues. Journal of Family Practice, 39, 564-568. 
Dalai-Lama, \& Cutler, H. C. (1998). The art of happiness: A handbook for living. New York: Riverhead Books.

Davies, C. G., Wortman, C. B., Lehman, D. R., \& Silver, R. C. (2000). Searching for meaning in loss: Are clinical assumptions correct? Death Studies, 24(6), 497-541.

Ehman, J. W., Ott, B. B., Short, T. H., Ciampa, R. C., \& Hansen-Flaschen, J. H. (1999). Do patients want physicians to inquire about their spiritual or religious beliefs if they become gravely ill? Archives of Internal Medicine, 159(1803-1806).

Fife, B. L. (1994). The conceptualization of meaning in illness. Social Science \& Medicine, 38(2), 309-316.

Folkman, S., \& Greer, S. (2000). Promoting psychological well-being in the face of serious illness: When theory, research and practice inform each other. Psycho-Oncology, 9(1), 11-19.

Franks, H. M., \& Roesch, S. C. (2006). Appraisals and coping in people living with cancer: A meta-analysis. Psycho-oncology, 15, 1027-1037.

Gall, T. L., \& Cornblat, M. W. (2002). Breast cancer survivors give voice: A qualitative analysis of spiritual factors in long-term adjustment. Psycho-Oncology, 11, 524-535.

Gilligan, P., \& Furness, S. (2006). The role of religion and spirituality in social work practice: Views and experiences of social workers and students. British Journal of Social Work, 36, $617-637$.

Guba, E. G. (Ed.). (1990). The paradigm dialog: 4 paradigms of positivism, post-positivism, critical theory and constructivism. Newbury Park, Calif.: Sage Publications.

Gunaratana, H. (1991). Mindfulness in plain English. Boston: Wisdom Publications. 
Highfield, M. F. (1997). Spiritual assessment across the cancer trajectory: Methods and reflections. Seminars in Oncology Nursing, 13(4), 237-241.

Ho, D. Y. F., \& Ho, R. T. H. (2007). Measuring spirituality and spiritual emptiness: Toward ecumenicity and transcultural applicability. Review of General Psychology, 11(1), 62-74.

Ho, S. M. Y., Chan, C. L. W., \& Ho, R. T. H. (2004). Post-traumatic growth in Chinese cancer survivors. Psycho-Oncology, 13(6), 377-389.

Hodge, D. R. (2001). Spiritual assessment: A review of major qualitative methods and a new framework for assessing spirituality. Social Work, 46(3), 203-215.

Holland, J. M., Currier, J. M., \& Neimeyer, R. A. (2006). Meaning reconstruction in the first two years of bereavement: The role of sense-making and benefit-finding. Omega: The Journal of Death and Dying, 53(3), 175-191.

Jing, H. B. (2002). What Confucianism can offer for counselling? In C. L. W. Chan, F. M. Fan, S. M. Y. Ho \& M. P. Wong (Eds.), An exploration on Chinese culture and model of counseling (pp. 133-153). Beijing: University of Hong Kong - Qinghua University Counseling Research Centre (in Chinese).

Koenig, H. K., McCullough, M. E., \& Larson, D. B. (2001). Handbook of Religion and Health. New York: Oxford University Press.

Koenig, T. L., \& Spano, R. N. (1998). Taoism and the strength perspective. In E. R. Canda (Ed.), Spirituality in social work: New directions (pp. 47-65). New York: The Haworth Pastoral Press.

Komura, K., \& Hegarty, J. R. (2006). The appraisal of positive life changes following cancer diagnosis: An interview study. Palliative and Supportive Care, 4, 3-12. 
Lazarus, R. S., \& Folkman, S. (1984). Stress, appraisal, and coping. New York: Springer Publishing Co.

Lee, M. Y., Ng, S. M., Leung, P. P. Y., \& Chan, C. L. W. (2009). Integrative Body-Mind-Spirit social work: An empirically based approach to assessment and treatment. New York: Oxford University Press.

Leung, P. P. Y. (2007). Experiences and meaning reconstruction among Chinese women with breast cancer, Unpublished thesis. Doctoral dissertation, The University of Hong Kong, Hong Kong.

Leung, P. P. Y., Chan, C. L. W., Ng, S. M., \& Lee, M. Y. (2009). Towards body-mind-spirit integration: East meets West in clinical social work practice. Clinical Social Work Journal, 37(4), 303-311. doi: 10.1007/s10615-009-0201-9

Lincoln, Y. S. (2002). Emerging criteria for quality in qualitative and interpretive research. In K. D. Denzin \& Y. S. Lincoln (Eds.), The qualitative inquiry reader (pp. 327-345). London: Sage.

McClain, C. S., Rosenfeld, B., \& Breitbart, W. (2003). Effect of spiritual well-being on end-oflife despair in terminally-ill cancer patients. The Lancet, 361(9369), 1603.

Moadel, A., Morgan, C., Fatone, A., Grennan, J., \& Carter, J. (1999). Seeking meaning and hope: Self-reported spiritual and existential needs among an ethnically-diverse cancer patient population. Psycho-Oncology, 8, 378-385.

Morrow, S. L. (2005). Quality and trustworthiness in qualitative research in counseling psychology. Journal of Counseling Psychology, 52(2), 250-260.

Neimeyer, R. A. (2001). Meaning reconstruction and the experience of loss. Washington, DC: American Psychological Association. 
Nhat-Hanh, T. (1991). Peace is every step: The path of mindfulness in everyday life. New York: Bantam Books.

Nhat-Hanh, T. (1995). Living Buddha, living Christ. New York: Riverhead Books.

Padgett, D. K. (2008). Qualitative methods in social work research (2nd ed.). Los Angeles, Calif: Sage Publications.

Park, C. L., \& Folkman, S. (1997). Meaning in the context of stress and coping. Review of General Psychology, 1(2), 115-144.

Patton, M. Q. (2002). Qualitative research and evaluation methods (3rd ed.). Thousand Oaks, CA: Sage Publications.

Ramaswami, S., \& Sheikh, A. (1989). Buddhist psychology: Implications for healing. In A. Sheikh \& K. Sheikh (Eds.), Eastern and Western approaches to healing: Ancient wisdom and modern knowledge (pp. 91-123). New York: Wiley-Interscience.

Riessman, F. (1965). The "helper" therapy principle. Social Work, 10(2), 27-32.

Rubin, J. B. (1996). Psychotherapy and Buddhism: Toward an integration. New York: Plenum Press.

Samarel, N., Fawcett, J., Krippendorf, K., Paicentino, J., Eliasof, B., Hughes, P., et al. (1998). Women's perceptions of group support and adaptation to breast cancer. Journal of Advanced Nursing, 28, 1259-1268.

Siporin, M. (1983). The therapeutic process in clinical social work. Social Work, 28(3), 193-198.

Strauss, A., \& Corbin, J. (1990). Basics of qualitative research: Grounded theory procedures and techniques. Newbury Park, CA: Sage.

Taylor, S. E. (1983). Adjustment to threatening events: A theory of cognitive adaptation. American Psychologist, 38(11), 1161-1173. 
Teasdale, J. D., Segal, Z. V., Williams, J. M. G., Ridgeway, V. A., Soulsby, J. M., \& Lau, M. A. (2000). Prevention of relapse/recurrence in major depression by mindfulness-based cognitive therapy. Journal of Consulting and Clinical Psychology, 68., 615-625.

Thornton, A. A. (2002). Perceiving benefits in the cancer experience. Journal of Clinical Psychology in Medical Settings, 9(2), 153-165.

Thune-Boyle, I. C., Stygall, J. A., \& Keshtgar, M. R. (2006). Do religious/spiritual coping strategies affect illness adjustment in patients with cancer? A systematic review of literature. Social Science \& Medicine, 63, 151-164.

Tsuei, W. (1992). Roots of Chinese culture and medicine. Selangor Darul Ehsan: Pelanduk Publications.

Tu, W. M. (1985). Confucian thought: Selfhood as creative transformation. Albany: State University of New York Press.

Tu, W. M. (1998). Humanity and self-cultivation: Essays in Confucian thought. Boston: Cheng \& Tsui Co.

Tu, W. M., \& Tucker, M. E. (2003). Confucian spirituality. New York: Crossroad Publishing.

Tucker, M. E. (2003). Introduction. In W. M. Tu \& M. E. Tucker (Eds.), Confucian spirituality (Vol. 2, pp. 1-35). New York: Crossroad Publishing.

Wilber, K. (2000). Integral psychology: Consciousness, spirit, psychology, therapy. Boston: Shambhala Publications, Inc.

Yu, Y. S. (2003). Between the heavenly and the human. In W. M. Tu \& M. E. Tucker (Eds.), Confucian spirituality (Vol. 1, pp. 62-80). New York: Crossroad Publishing. Zebrack, B. J. (2000). Cancer survivor identity and quality of life. Cancer Practice, 8(5), 238242. 
Table 1

Summary of Demographic Characteristics of Informants $(N=26)$

\begin{tabular}{|c|c|c|}
\hline Characteristics & Number & Percent \\
\hline \multicolumn{3}{|l|}{ Age } \\
\hline $21-30$ & 1 & 3.8 \\
\hline $31-40$ & 2 & 7.7 \\
\hline $41-50$ & 9 & 34.6 \\
\hline $51-60$ & 12 & 46.2 \\
\hline $61-70$ & 2 & 7.7 \\
\hline \multicolumn{3}{|l|}{ Time since diagnosis } \\
\hline 1 year & 1 & 3.8 \\
\hline $2-3$ years & 4 & 15.4 \\
\hline $4-5$ years & 14 & 53.8 \\
\hline $6-9$ years & 7 & 26.9 \\
\hline \multicolumn{3}{|l|}{ Education } \\
\hline Primary school & 6 & 23.1 \\
\hline Lower secondary school & 3 & 11.5 \\
\hline Upper secondary school & 12 & 46.2 \\
\hline Diploma/university & 4 & 15.4 \\
\hline Postgraduate study & 1 & 3.8 \\
\hline \multicolumn{3}{|l|}{ Marital status } \\
\hline Single & 3 & 11.5 \\
\hline Married & 21 & 80.8 \\
\hline Divorced/widowed & 2 & 7.7 \\
\hline \multicolumn{3}{|l|}{ Religious affiliation } \\
\hline No religion & 11 & 42.3 \\
\hline Buddhist & 5 & 19.2 \\
\hline Christian (Protestant) & 5 & 19.2 \\
\hline Christian (Catholic) & 3 & 11.5 \\
\hline Ancestral worship & 2 & 7.7 \\
\hline \multicolumn{3}{|l|}{ Employment status } \\
\hline Homemaker & 8 & 30.8 \\
\hline Employed & 11 & 42.3 \\
\hline Retired/early retirement & 6 & 23.1 \\
\hline Full-time student & 1 & 3.8 \\
\hline
\end{tabular}


Table 2

Spiritual Themes in Chinese Women's Experience of Adjusting to Cancer Spiritual themes Sub-themes

\begin{tabular}{ll}
\hline Spiritual shock & 1. Asking why \\
Meaning-making & 2. Loss of "self" \\
& 1. Attributing a cause to the occurrence of cancer \\
2. Restructuring the perspective on life \\
Connectedness & 3. Construing benefits in the experience \\
& 1. Relationship with self \\
Transcendence & 2. Relationship with others \\
& 3. Relationship with God/Tien \\
& 1. Revival and transformation \\
& 3. Nurturing compassion \\
& 4. Living in the present moment \\
\hline
\end{tabular}




\section{Notes}

${ }^{1}$ Tien literally means Heaven. To most Chinese, Tien is the supreme power that governs the world.

${ }^{2}$ Mindfulness practice is derived from Buddhism. It is non-judgmental observation, the ability of the mind to observe without criticism. It is also referred to as the moment-to-moment awareness of one's experience, to stay in the here and now, and to attend deeply to everything that happens in the present moment, whether it is desire, thoughts, affects or memories, but not to pursue or reject them (Gunaratana, 1991; Nhat Hanh, 1995; Ramaswami \& Sheikh, 1989).

${ }^{3}$ Qigong is an exercise originating in ancient China. It combines motion with breathing and mind regulation. There are different forms of qigong, and all are believed to promote physical, mental, and even spiritual well-being (Tsuei, 1992 